This item was submitted to Loughborough's Research Repository by the author.

Items in Figshare are protected by copyright, with all rights reserved, unless otherwise indicated.

The importance of user ownership and positive user attitudes in the successful adoption of Community Information Systems

PLEASE CITE THE PUBLISHED VERSION

PUBLISHER

(C) IDEA Group

LICENCE

CC BY-NC-ND 4.0

REPOSITORY RECORD

Coombs, Crispin, Neil Doherty, and John Loan-Clarke. 2019. "The Importance of User Ownership and Positive User Attitudes in the Successful Adoption of Community Information Systems". figshare.

https://hdl.handle.net/2134/1221. 
This item was submitted to Loughborough's Institutional Repository by the author and is made available under the following Creative Commons Licence conditions.

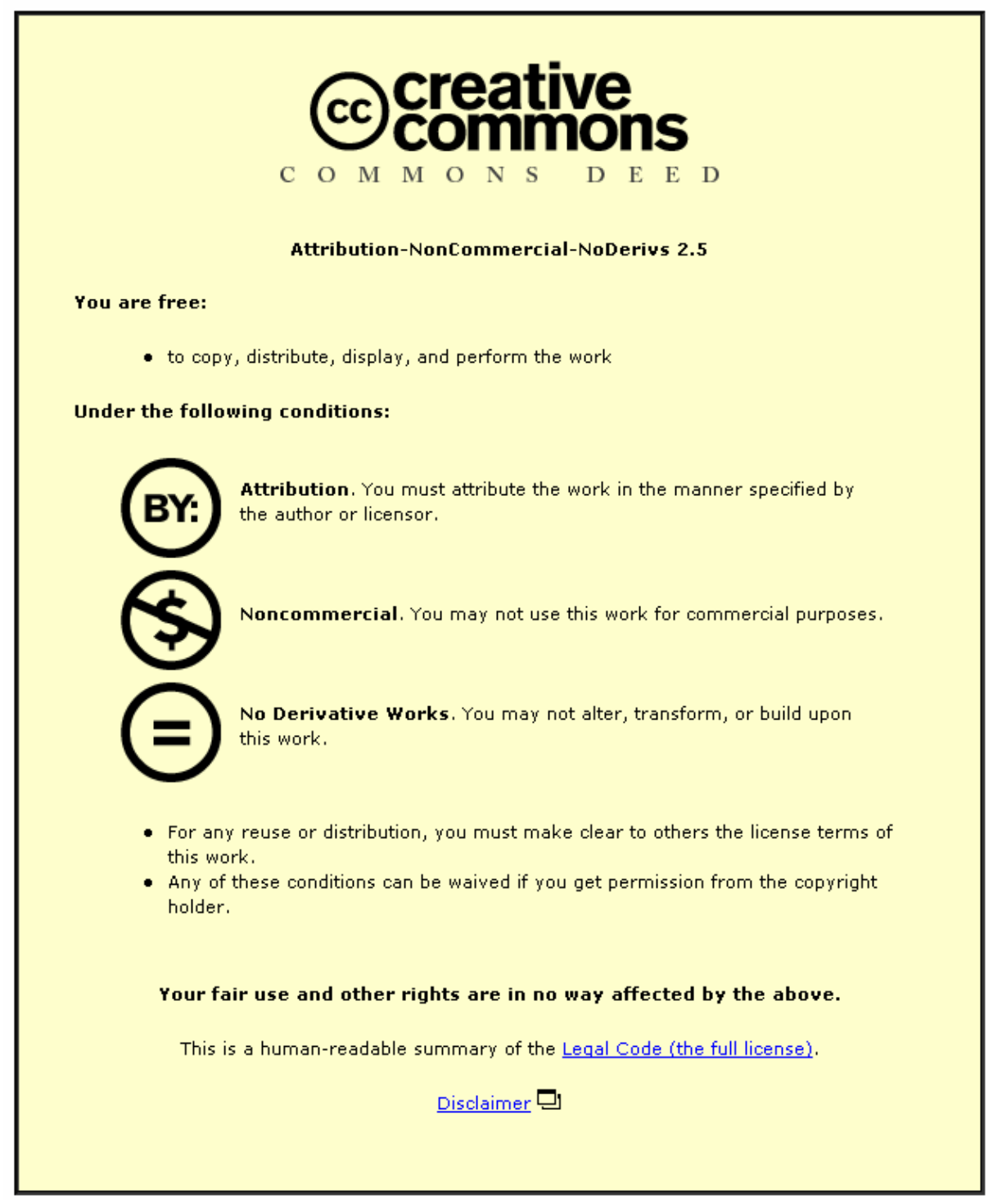

For the full text of this licence, please go to: http://creativecommons.org/licenses/by-nc-nd/2.5/ 


\section{Loughborough University}

\section{The Importance of User Ownership \& Positive User Attitudes in the Successful Adoption of Community Information Systems}

Coombs, C. R., Doherty, N. F., \& Loan-Clarke J.

The Business School, Loughborough University

Mailing Address:

Dr Neil Doherty,

The Business School,

Loughborough University,

Loughborough, LE11 3TU,

United Kingdom.

Telephone: 01509223128

Email: N.F.Doherty@ lboro.ac.uk

Fax: $\quad 01509223960$ 


\section{The Importance of User Ownership \& Positive User Attitudes in the Successful Adoption of Community Information Systems}

The challenge for the NHS is to harness the information revolution and use it to benefit patients (Rt. Hon Tony Blair, 1998) ${ }^{1}$

Key Words: Systems development; Success; Failure; NHS; Community Information Systems; United Kingdom

The factors that influence the ultimate level of success or failure of systems development projects have received considerable attention in the academic literature. However, despite the existence of a 'best practice' literature many projects still fail. The record of the National Health Service has been particularly poor in this respect. The research reported in this paper proposes that two additional factors; user ownership and positive user attitudes warrant further development and investigation. The current study investigated these two factors in a homogenous organisational sector, Community NHS Trusts, using a common type of information system, in order to eliminate the potentially confounding influences of sector and system. A multiple case-study design incorporating five Community Healthcare Trusts was utilised. The key results from the analysis indicated that both user ownership and positive user attitudes were important mediating variables that were crucial to the success of a CIS. In addition, it was also identified that the adoption of best practice variables had a dual role, directly influencing the level of perceived success but also facilitating the development of user ownership and positive user attitudes. These results will be of particular interest to practising IM\&T managers in the NHS and also to the wider academic research community.

${ }^{1}$ All our Tomorrow's Conference, Earls Court, London. $2^{\text {nd }}$ July 1998. 


\section{Introduction}

Over the past twenty years the level of penetration and sophistication of information technology has grown dramatically, with computer-based information systems actively supporting all key business processes and significantly enhancing both the operational effectiveness and the strategic direction of organisations of all types. The UK's National Health Service (NHS) is one, particularly large and complex, organisation that has been keen to harness the potential of IT to enhance its administrative, managerial and clinical performance. Unfortunately, in both the public and private sectors, the successful acquisition and introduction of information technology is still dogged by high failure rates (Lyytinen \& Hirschheim, 1987; Kearney, 1990; Hochstrasser \& Griffiths, 1991; Clegg et al., 1997). More specifically, there is much evidence to suggest that the NHS's record has been particularly poor, with respect to the successful deployment of computer-based information systems (for example: National Audit Office, 1991; Keen, 1994; National Audit Office, 1996).

There is, therefore, still a pressing need for well-focussed research to provide insights into how levels of failure can be reduced from both a general perspective and with regard to the NHS in particular. To help investigate these issues a research project was initiated to explore the factors that affect the success of Community Information Systems (CIS) within the NHS. It was envisaged that the application of CIS within the community healthcare sector would provide a particularly fertile research domain for the following two reasons:

1. Community Trusts form a reasonably homogeneous organisational sector, distinct from the acute sector and community information systems provide different instances of a common type of application; consequently the number of confounding factors in the study are greatly reduced;

2. Two recent official reports (Audit Commission, 1997; Burns, 1998) have identified a high degree of variability in the quality of CIS with many existing systems failing to deliver the anticipated benefits. Consequently, it would be possible to compare and contrast the experiences of Trusts, which had experienced a range of different outcomes.

The initial phases of this project entailed a detailed case study, based upon interviews with a wide variety of staff at Central Nottinghamshire Healthcare (NHS) Trust $(\mathrm{CNHT})^{2}$ and a survey of IT managers within Community Trusts (Coombs et al., 1998; Coombs et al., 1999). These studies provided important insights into the role and impact of CIS and helped to focus the research objectives, for the later stages of the project. More specifically, in addition to confirming the 
importance of factors such as training; senior management commitment and participation; testing and user involvement, the results from these preliminary studies, also indicated the critical roles of user ownership and positive user attitudes. As these latter factors have not, to date, received the attention they warrant in the academic literature, a follow-up, qualitative study was initiated to explicitly review their importance.

The paper is organised into several sections. The following section presents a summary of the relevant information systems literature before presenting and justifying three research objectives. The justification for, and implementation of, the multiple case-study research design and research methods are discussed in section three. The research results are presented in a series of tables and diagrams, which are discussed in the fourth section. Finally, the importance of this research for the NHS and other organisations is assessed in the concluding section.

\section{Contextual Background and Research Objectives}

In the past twenty years much interest has been generated in the identification of factors critical to the successful outcome of systems development projects (For example: Rademacher, 1989; Cerullo, 1980; Yap et al., 1992; Sauer, 1993; Willcocks \& Margetts, 1994; Whyte \& Bytheway, 1996; Flowers, 1997; Li, 1997). The aim, therefore, of this section is to review the most common best practice factors highlighted in the literature, prior to reviewing the potentially important contributions of positive user attitudes and user ownership to the successful outcome of a systems development project. In so doing, the objectives of this research are established.

\subsection{Best Practice in Systems Development Projects}

A number of empirical and in-depth studies have been conducted which examine success factors in the development and implementation of information systems. These and other studies have helped to focus IT professionals' attention on the importance of factors such as: user involvement (Wong \& Tate, 1994; Whyte \& Bytheway, 1996); senior management commitment (Cerullo, 1980; Sauer, 1993); staff training (Miller \& Doyle, 1987; Whyte \& Bytheway, 1996); systems testing (Ennals, 1995; Flowers, 1997) and user support (Miller \& Doyle, 1987; Govindarajulu \& Reithel, 1998). There is, therefore, a well-documented body of 'best practice' knowledge that should guide the IT practitioner in the effective development and implementation of information systems. However, there exists a paradoxical situation in that far too many projects still fail, despite the availability of this body of knowledge, which should help to promote success. Why in so many instances should this be the case? It could perhaps be that the advice is either: blatantly disregarded; not universally

institution. 
appropriate; not well disseminated or not always possible to heed. Alternatively it might be that the adoption of existing best practice guidelines is not, by itself, sufficient to ensure the successful outcome of systems development projects.

\subsection{The Importance of User Ownership}

Van Alstyne et al. (1995) have stated that: 'ownership is critical to the success of information systems projects' with the key reason for this being 'self-interest; owners have a greater vested interest in system's success than non-owners' (p. 268). However, Clegg et al. (1997) suggest that in far too many projects it is the developers rather than the users and user managers who own the system, which may have undesirable consequences for the system's performance. Unfortunately, this apparently important concept has received relatively little explicit attention in the information systems' literature. Where ownership has been addressed in studies it has typically been in the context of increasing user acceptance (Robey \& Farrow, 1982; Guimaraes \& McKeen, 1993) or minimising user resistance (Markus, 1983, Beynon-Davis, 1995). Based upon this review of the literature, and the results of the preliminary stages of this research, the following working definition for user ownership has been derived:

'The state in which members of the user community display through their behaviour, an active responsibility for an information system'.

To clarify this definition, it is necessary to add the two following qualifiers. Firstly, it must be stressed that whilst it is highly desirable that user ownership should be exhibited by the whole user community, throughout all stages of the system's development and operation, this may not always be the case. Secondly, it should be noted that the users may not be able to claim exclusive ownership of the system, as ownership will be shared with members of the steering committee and the development team, especially in the system's developmental stages.

\subsection{The Importance of Positive User Attitudes}

In purely quantitative terms the importance of positive user attitudes has probably received more attention in the literature than user ownership. It is, for example, widely recognised that it is desirable to attain positive user attitudes as this may have a beneficial impact upon user behaviour, ultimately influencing user acceptance of the system (Lucas, 1978 \& 1981; Zmud, 1983; Ginzberg et al., 1984; Joshi, 1990 \& 1992). More specifically, Grantham \& Vaske (1985) and Davis (1993) have suggested that positive user attitudes are an important predictor of system's usage. In the context of this research, the following working definition for positive user attitudes has been derived: 
'The state in which members of the user community display positive opinions and beliefs towards the information system'.

It should be noted that, as for user ownership, levels of positive user attitude may vary between different members of the user community and also between different phases of the system's development and operation. Finally, the working definition of positive user attitudes appears in many ways similar to constructs used in other studies, such as 'user satisfaction' (DeLone \& McLean, 1992), 'user information satisfaction' (Bailey \& Pearson, 1983; Srinivasan, 1985) or 'user reactions' (Clegg et al., 1997). However, there is one important distinction; whilst user satisfaction, user information satisfaction and user reactions are typically formulated as responses to a recently implemented system, positive user attitudes is a state which can begin from the project's inception and continue throughout the system's working life.

\subsection{Critique of the Literature and Establishment of Research Objectives}

Unfortunately, despite the substantial body of knowledge with regard to best practice within systems development projects the incidence of systems failure and systems under-performance remains stubbornly high. This may in part be due to the following limitations with regard to existing literature.

1. The 'best practice' literature, which is extensive, has limitations in terms of either depth or generalisibility. For example, survey studies, whilst providing the breadth of coverage, lack the capacity to effectively deal with the complexity of the system development process (Sauer, 1993). By contrast, case studies, whilst far better suited to handling the complexities of systems development, either relate to only one case or focus upon a number of unrelated cases; in both instances the generalisibility of findings is problematic.

2. Whilst some studies have noted the importance of user ownership and positive user attitudes, little work has specifically targeted these factors to identify why they are significant and how they can be achieved. Furthermore, this research has typically been conducted in isolation from the research into best practice. For example, most studies of best practice factors (for example: Miller \& Doyle, 1987; Whyte \& Bytheway, 1996; Doherty et al., 1998) do not include user ownership and positive user attitudes. Consequently, it is difficult to judge the relative importance of these factors and their relationship with other best practice factors.

To overcome these weaknesses, a qualitative study was initiated, targeting the development and implementation of community information systems. This approach isolated a single organisational sector, Community Trusts, in which different instances of a standard application of IT are currently 
being applied and ensured that the following research objectives could be addressed:

1. Identification of the relationship between the ability of the project teams to encourage user ownership and the resultant level of success or failure of the operational information system;

2. Identification of the relationship between the ability of the project teams to encourage positive user attitudes and the resultant level of success or failure of the operational information system;

3. Identification of the relationships between user ownership, positive user attitudes, other best practice factors and the resultant level of success or failure of the operational information system.

It was envisaged that through the exploration of these issues new evidence could be provided with respect to the importance and role of user ownership and positive user attitudes in systems development projects. In addition, it would be possible to provide advice to IT practitioners on the importance of taking steps to foster user ownership and positive user attitudes. More specifically, the research should provide important insights into the successful development and implementation of information systems within the NHS in general, and Community Trusts in particular.

\section{Research Methodology}

Doherty et al. (1998) have noted that existing research on best practice has tended to focus on developing a critical set of factors affecting IT implementation success with less emphasis being placed on 'how' and 'why' these factors interact together to produce either success or failure. Gable (1994) and Pare and Elam (1997) advocate the greater use of case study research to explore and develop an increased understanding of these complex relationships. The aim of this section is to provide an overview of the methods by which a case study-based piece of research was initiated and executed to explore the objectives described at the end of the previous section.

\subsection{Research Design}

The initial stages of this research project comprised a detailed case study at a single Community Trust and a survey of all Community Care (NHS) Trusts in the UK. Whilst both of these studies provided important insights and facilitated the design of the research presented in this paper, both can be criticised from a methodological perspective. For example, whilst it has been argued that 'case study research is particularly appropriate for the study of information systems development, implementation and use within organisations' (Darke et al., 1998, p. 278), Galliers (1992) notes that case studies are usually restricted to a single event or organisation and that it is difficult to collect similar data from a sufficient number of similar organisations making it difficult to generalise from 
case study research. Similarly, it can be argued that survey-based studies, whilst providing the breadth of coverage, lack the capacity to effectively deal with the complexity of the system development process (Sauer, 1993).

Multiple case studies however, allow the study of phenomena in more diverse settings and facilitate cross-case analysis and comparison. This multiple approach allows the researcher to confirm that findings are not being unduly influenced by confounding variables unique to individual research settings (Cavaye, 1996). In addition, multiple cases may also be used either to predict similar results (literal replication) or contrasting results for predictable reasons (theoretical replication) (Yin, 1994, p. 46). Based on the desire to explore and interpret the complex relationships between best practice, user ownership, positive user attitudes and success a multiple case study approach was undertaken.

\subsection{Research Instrument Design}

Past literature on best practice and organisational impact as well as the evidence from the initial case study research and the questionnaire survey were used to develop questions to be included in a semistructured interview schedule. The choice of a semi-structured interview over a standardised interview was made because of the exploratory nature of the research and the fact that it would not have been possible to create a fully structured guide from current knowledge (Diamantopoulos \& Souchon, 1996). The interview schedule had four sections: biographical/introductory; the adoption of best practice variables; the attainment of user ownership and positive user attitudes; and the determinants of success. The final section of the interview consisted of a short questionnaire that used a five point Likert scale to measure various aspects of the perceived system success. The success measures were adapted from the six generic measures developed by DeLone \& McLean (1992) and addressed both user and management perspectives on various aspects of the system. Each interviewee was sent a letter outlining the aims of the research project and indicating the specific areas that would be explored through the interviews.

\subsection{Targeting \& Execution of the Interviews}

In studying the responses to the questionnaire survey it became clear that one particular community information system (Comwise, designed by Systems Team) was most common among respondents. It was therefore possible and desirable to concentrate on this sample as it removed the confounding factor of variations in system design from the analysis. However, in order for the results from the Comwise sample to be generalised to the rest of the respondents it was necessary to confirm that the Comwise sample was representative of all the respondents. Statistical means and variances were calculated for each question on the survey and compared for both the main group of respondents and the Comwise sample. No significant differences between the means or variances for each group were 
identified and consequently it was concluded that the Comwise sample was representative of the main group of respondents to the questionnaire. The Comwise sample group consisted of 18 Trusts and had a further advantage in that the performance of the system in different Trusts appeared to vary considerably as perceived by the respondents to the questionnaire survey. Therefore, a multiple case study approach would enable us to study a range of Trusts that were using the same CIS but were producing contrasting results in terms of success.

On the basis of their perceived CIS performance a range of five Trusts were contacted and in each case the initial contact was through the respondent to the questionnaire, either the IM\&T Manager or the Information Manager. An interview was conducted with each of these key informants at the end of which requests were made for additional members of the Trust to interview. It was considered particularly important that staff from areas outside the Information and IT Departments of the Trust be interviewed to record their perspective on the use of a CIS. The clinicians form the largest stakeholder group that use a CIS and one of the key measurements of the success of a CIS is the clinicians' satisfaction with the system. A criticism frequently levelled at quantitative IS research is that it tends to concentrate on documenting and studying the views of IS professionals who have a clear vested interest in the success of the system. Consequently the opportunity to interview and document other staff views towards the system was considered to be of great importance.

The key informants were asked to identify an administrator, a clinical manager and a clinical user who would be willing to participate in the study. As can be seen, from the breakdown of interviewees presented in table 1, it was not always possible, for practical reasons, to achieve the desired mix of informants, but sufficient numbers of informants participated from each Trust to ensure that the sample reflected a range of views.

\section{Insert Table 1 about here}

In addition to participating in the interviews, the IM\&T Managers were asked to provide, if possible, documentary evidence, such as published articles, internal reports or newsletters, which were used to help contextualise, explain and verify the interview responses. As can also be seen from the information presented in table 1, such information was forthcoming in a number of cases. Each interview was conducted, in-situ, at the Trust and lasted approximately an hour. To ensure the validity of the interview process, the informants were asked to supply specific evidence and examples to support their assertions. In the vast majority of cases, the face to face interview was complemented by a follow-up phone call that was used to clarify issues and attain supplementary information. Both the initial interviews and the follow-up phone calls were tape recorded and later transcribed verbatim. 
In terms of the characteristics of the Trusts visited, table 2 shows that although there was some variation in the range of services they provided and premises they used, they also exhibited a number of common features. The Trusts all operated on a decentralised basis with a small number of hospitals and multiple health centres. Most importantly, the same core staff groups used the system within each Trust. Similarly, because all the Trusts are based within the community healthcare sector they are guided by common policy and priority goals identified by the Department of Health. Furthermore, table 2 also demonstrates that all the Trusts were using the same software package and supplier for their community information systems. Consequently, by targeting these five Trusts it was possible to minimise the effect of confounding factors such as healthcare sector, type of system and system design.

\section{Insert Table 2 about here}

\subsection{Data Analysis Strategy}

The analysis follows the three concurrent activities identified by Miles \& Huberman, (1994, p. 10) of data reduction, data display and conclusion drawing/verification. This approach is necessary to ensure that the researcher does not become overloaded from unreduced data transcripts and their information processing abilities impaired (Faust, 1982). Data reduction was conducted on each interview transcript using mainly 'in-vivo' codes, that is codes derived from phrases used repeatedly by informants (Strauss \& Corbin, 1990). In-vivo codes (as opposed to codes determined prior to the analysis) are appropriate when the research is essentially exploratory and are more useful in identifying new variables than adopting constrained literature-based codes (Diamantopoulos \& Souchon, 1996). In addition, marginal remarks were used during the coding period to add clarity and meaning to the transcripts as well as having the ability to help revise and improve the coding structure (Chesler, 1987).

From the codes it was possible to develop a series of within-case matrix displays for each Trust. The within-case analysis was primarily conducted using the following three displays:

1. Time ordered displays: The time ordered display was used to show the variations in each variable over time and the major events during the CIS project identified by respondents. This display is primarily descriptive although it does have the value of preserving the historical flow and permitting a good look at the chain of events (Miles \& Huberman, 1994, p. 110);

2. Conceptually ordered displays: This display was used to study the variables in more depth and 
generate more explanatory power. A thematic conceptual matrix was developed for each case to study the manifestation of the variable, the facilitators and inhibitors directly related to that variable and any solutions that had been subsequently proposed or adopted (Miles \& Huberman, 1994, p. 131);

3. Effects matrix: Finally an effects matrix was also constructed for each Trust. This display concentrates on the outcomes of each of the variables concerned and their effects on other variables and areas associated with the CIS project. Each variable was analysed for positive and negative effects on specific outcomes and whether they were considered by informants to be direct or indirect relationships (Miles \& Huberman, 1994, p. 137).

Following the within-case analysis the displays were synthesised into a series of fewer cross-case displays. The cross-case analysis took the form of a composite thematic conceptual matrix (Miles \& Huberman, 1994, p. 183) and a causal network display (Miles \& Huberman, 1994, p. 222). The composite thematic conceptual matrix allowed us to study the similarities and differences between the facilitators and inhibitors for each variable. The causal network was developed from a series of linear sub-models that displayed the linkages between variables more clearly before they were synthesised into a single overall causal model. It is primarily the results of these cross-case displays that are presented in the following section of this paper.

\section{Research Results}

The research findings are reported in this section by presenting evidence in the form of specific examples and comments gathered through the interview process. To make the discussion of these findings more meaningful they are related to the three specific research objectives identified in section 2.4.

\subsection{The relationship between user ownership and success}

To explore the relationship between user ownership and success, informants were specifically asked during the interviews whether user ownership was occurring within their Trust and whether achieving user ownership had been planned or was occurring as a reaction to the development and operation of the system. Furthermore, each interviewee was asked to assess the effect that achieving user ownership was having on the operation of the CIS.

From the results of the cross-case analysis it was clear that there was a mixed experience across the Trusts with respect to user ownership. In four out of the five Trusts (A, B, C \& D) it was found that 
achieving user ownership had been planned. However, only informants in one Trust (A) said that user ownership was already occurring at high levels. As one clinical user noted: 'there is ownership because we use it to inform our clinical practice' and 'I think it [user ownership] was a deliberate policy by IT and I think the new Head of Information will extend that even further than it is now'.

Informants in Trust B provided contrasting views on the occurrence of user ownership indicating that user ownership was perceived to be occurring at high levels in some areas, but not others. For example, whilst the IM\&T Manager (B) stated: 'this is something the Head of Information has been working towards and this process is now coming where we are saying this is your system, what do you want us to record? Whereas before they were told what to record', a manager (B) suggested: 'I don't think staff have ever had ownership of the system and I think that is an extremely important issue'.

Informants in Trust C stated that user ownership was starting to occur, but only at moderate levels so far, with one manager (C) noting: 'we may be a little hard on ourselves but we still don't believe that we have got adequate user ownership'. However, in the majority of the Trusts (A, B \& C) high levels of user ownership were expected in the future, once greater access to information was provided (A \& B) and the CIS was fully implemented (C). By contrast, informants in Trusts D and E indicated that there was little or no user ownership occurring. For example, in Trust D a clinical user noted 'it has certainly been useful but I wouldn't have thought of it as our system', whilst the IM\&T Manager at Trust E reflected: 'I think users see it as part of the daily grind of filling in these Daily Diary Sheets and so on and that's it really'. One manager at Trust E summarised the situation more bluntly: 'its just a necessary evil'. However, it was only the informants from Trust E who stated that user ownership had not been planned and was unlikely to occur in the future.

However, despite the range of experiences in achieving user ownership, there was a clear consensus across informants in all the Trusts, of the importance of user ownership to the ultimate success of a CIS. In three of the five Trusts (A, B \& C) user ownership was identified as having particular importance in avoiding failure with informants making the following comments:

- 'The Trust is very reliant on user ownership because it is a Community Trust and staff are very decentralised. If the staff, the clinicians on the ground, don't own the system, feel how essential it is, it would be a complete failure' (clinical user, A);

- 'Achieving user ownership will be the deciding factor of whether they use the system or not’ (IM\&T Manager, B);

- 'If they [clinical staff] don't get ownership they will rely on non-clinical people trying to tell them how to use it which won't work' (IM\&T Manager, C). 
It was interesting to note that the importance of user ownership was also recognised in Trust E, with a clinical manager commenting that: 'the Trust needs to encourage user ownership', even though all informants from the Trust recognised that they had not experienced user ownership.

More specific benefits from achieving user ownership were also identified by respondents. For example, the IM\&T Manager (A) stated that: 'having user ownership has meant that users are in control of their information' and a clinical user (A) noted that: 'ownership is about recognising and seeing the potential to develop things that are going to be clinically useful. Without the ownership you wouldn't be getting the ideas being generated and pushing the development of it [CIS] which in turn is improving patient care'. Similarly, the IM\&T Manager (C) stated that: 'I think once they [clinicians] own it they will try and optimise its use and they will try and explore different ways in which the system can be used to improve the service'.

The importance of attaining user ownership has also been highlighted by the experiences of those Trusts that failed to achieve it. As a manager from Trust B noted 'without ownership of the data they [clinicians] don't feel they are involved or they are controlling it then we are going to have problems with the quality'. Similar views were expressed at both Trusts D and E. For example, the IM\&T Manager (D) stated that: 'I think the main problem is the quality of the data. They are not interested in what is going in so the quality is poor. That then undermines the quality of the reports that are pulled off'. Similarly, a clinical manager (E) noted: 'It's not worthwhile entering the data from their [clinicians] point of view, they can't access the data and not being able to get the answers that they want further increases the amount of cynicism associated with the system'.

The relationships that have been identified above clearly provide strong evidence to suggest that there is a relationship between user ownership and success. Furthermore, it has been demonstrated that the relationship can have either a positive or negative effect on the overall perceived success of a CIS, depending on how well user ownership is addressed during the systems development project.

\subsection{The relationship between positive user attitudes and success}

The cross-case analysis of user attitudes indicated that all Trusts planned to develop positive user attitudes during the development, implementation and use of their respective community information systems. Informants at Trusts A and C stated that user attitudes were positive towards the CIS and that this positive attitude was thought likely to continue in the future. More specifically, the following examples were cited as evidence of positive user attitudes: an increased demand for reports (IM\&T Manager, A; clinical manager, C); efforts by users to improve data quality (IM\&T Manager, A); and general positive comments about the CIS during staff meetings (clinical user, A; clinical manager, C). 
Furthermore, in Trust $\mathrm{C}$ it was envisaged that the planned increases in access to information would further develop and enhance the users' positive attitudes. As one clinical user (C) commented: 'we are going to get more out of the system for our [the clinical staff] benefit looking at what we do in terms of monitoring things on various diagnoses and incidents'.

Informants at Trusts B and D gave mixed responses as to whether they perceived user attitudes to be positive; indicating that there was a variation in perceptions towards the CIS across these Trusts. However, the IM\&T Manager (B) did expect user attitudes to be more positive in the future commenting that: 'once we get the printers out there and the users start using the system and they start asking for more information it is going to be a great deal easier to give users information'. Only informants at Trust E stated that although attempts had been made to develop positive user attitudes, at the time of interviewing attitudes were not positive and they were unsure whether attitudes would improve in the future. It was perceived by informants in Trust E that clinicians only considered their interaction with the system to be a mandatory routine that provided no personal benefit. Specific comments included: 'it's just what they call a necessary evil because of Billing' (manager, E); 'positive is not the right word. It is part of a thing that we have to do, so we do it' (clinical user, E); and 'the users tend not to ask for information. A lot of them don't seem to be interested' (IM\&T Manager, E).

The quality and availability of the information output was perceived as being key to the attainment of positive user attitudes:

- 'The single most important factor is that we have access to the information' (clinical user, A);

- 'I think in terms of report writing, people are now coming to me and saying, can I get this information? How is this done? That is the best news, that they are taking it seriously and thinking maybe I can do something with it.' (clinical user, C);

- 'I think there is a lot of evidence of positive user attitudes in the way people have adapted to using the system. Where it [CIS] has been a success they [clinicians] are starting to get ideas for the development of the system and people are starting to look at the information in terms of what can be collected' (clinical manager, C);

- 'If you could get meaningful information out, then I think it would fire them up and they would be interested' (manager, E).

There was general agreement, from informants in all Trusts, that there is a significant relationship between user attitudes and success. For example, it was noted that once positive user attitudes had been attained, there were significant resultant benefits with respect to the quality of the data input. As 
one clinical user (A) noted: 'I think the biggest benefit is staff are motivated to record and reflect what we do accurately'. This view was endorsed IM\&T Manager (A) who noted: 'they are committed to doing it [record information] and they are committed to ensuring that their colleagues also do it [record information] and record accurately'. These views were echoed by an IM\&T Manager from Trust B who noted: 'it has made the user more responsible for feeding in the data in on time and correctly'.

Conversely, in Trust E where positive user attitudes were not identified, there have been severe problems with data quality. The IM\&T Manager (E) stated that: 'generally the staff aren't very interested in the activity once they have done it' and as a result, 'we discovered that anything that we tried to get from it [CIS] was corrupted by poor data quality and I think we went into a little bit of despondency then'. The negative impact of failing to achieve positive user attitudes was also recognised in Trust D, with the IM\&T Manager noting that staff: 'always blame the system for the errors, it's never their own errors that have caused the problems'.

The above findings suggest that information and data quality may be inextricably linked to the attainment and retention of positive user attitudes. In three Trusts (A, B \& C) where information quality and accessibility were perceived as being high, positive user attitudes have resulted. This in turn encouraged the users to be more attentive to the quality of their data input, which ultimately enhanced the effectiveness of the system. Conversely, in Trusts D and E, where there has been poor quality in terms of the information output then this has contributed to negative user attitudes, which ultimately undermined the perceived success of the CIS.

\subsection{The relationship between best practice, user ownership, positive user attitudes and success}

During the interviews the role of several best practice variables and their relationship with the overall perceived success of the CIS were also reviewed. The importance of these best practice variables to information system success has already been established in the literature (see section 2) and the responses from informants strongly supported the existing research. However, the actual occurrence of these best practice variables did vary between the different Trusts as shown in table 3 . This table indicates that Trust A, whose informants were generally very positive about the impact of their system, were very successful in the adoption of best practice. By contrast, the findings for Trust E, whose informants were far less positive about the impact of their system, indicate that they were the least successful in the adoption of best practice. The remaining three Trusts were generally better than Trust $\mathrm{E}$ but behind Trust A, both in the adoption of best practice and in terms of the perceived success of their systems. These results suggest that those Trusts that adopt high levels of all the best practice variables are more likely to achieve higher levels of perceived success associated with their CIS. 


\section{Insert table 3 about here}

In addition, informants were also asked to discuss the main treatment approaches that had been adopted in their Trusts to achieve user ownership and positive user attitudes. In terms of achieving user ownership a range of treatment approaches were identified, however, there was clearly a strong emphasis on the role of best practice variables as the foundations for these methods. For example, in Trust A it was highlighted that high levels of senior management commitment had led to the provision of resources, which facilitated the delivery of regular, relevant reports to clinical staff and ultimately encouraged ownership (clinical user). User involvement and user training were also cited as being facilitators for developing user ownership with a clinical user at Trust A stating that 'we are using the CIS to support our clinical issues and I think that is because of the involvement of clinicians right from the very start' and 'I think people who went to the training sessions came out recognising that they would have to implement something that was going to be valuable to them in their clinical practice so the focus and the message from the training was very much to do with ownership'. Best practice variables were also identified as facilitating user ownership at Trusts B and C with senior management commitment resulting in the appointment of a systems champion (B). Senior managers were also seen as making a concerted effort to give out a positive message that the CIS was for clinical staff benefit (C). User involvement demonstrated that the CIS was for staff benefit and helped to allay the fears of users (C) and training helped to introduce the users to the concepts behind using the information that will be available from the CIS (C).

However, as well as being effective treatment approaches, the lack of certain best practice variables were also identified as being significant inhibitors to the development of user ownership. Low levels of senior management commitment and participation were identified as contributing to the problems of clinicians attaining access to information, ultimately resulting in low user ownership (D \& E). Additionally, low levels of user involvement resulted in the CIS being seen as being imposed on clinicians rather than being focused upon clinical needs (E). Finally, where clinicians had not been involved in deciding what information was collected, so the clinicians have not perceived the information to have any value for them (D \& E).

As well as affecting the development of user ownership, informants also indicated that user attitudes were also frequently influenced through the adoption of best practice variables. The importance of having a well-balanced project team in developing positive user attitudes was identified in Trusts A, B and $\mathrm{C}$ with informants stating that: 
- 'I think the thing that has been most important is having somebody with a clinical background. I have a clinical background and I think the thing that has made the difference is that clinicians have faith in you because they think you understand what you are doing' (IM\&T Manager, A);

- 'I think they [clinicians] had more of an affinity with the Head of Information because of his clinical background. I think they felt he was one of their own and their needs would be understood and their requirements would be addressed' (manager, B);

- 'The fact that we have got a Clinical Development Advisor in place is helping to develop the system as well which from a clinician's point of view is excellent' (clinical user, C).

Similarly, good management of user expectations (A \& C) and good quality user training with friendly staff, (A, C \& D) were also cited as directly contributing to positive user attitudes.

It was also significant to note that as in the case of user ownership, not adopting certain best practice variables were also perceived to directly inhibit the development of positive user attitudes. A lack of senior management commitment to using information, low levels of training for clinicians and not realising user expectations were all identified at Trust $\mathrm{E}$ as having a negative effect on user attitudes. Similar problems in terms of managing user expectations were also cited as causing negative user attitudes at Trusts B and D. In addition, low senior management commitment at Trust D resulted in low levels of resource provision for the CIS and frustration among clinical users, which was also cited as directly contributing to low user attitudes.

This evidence suggests that best practice variables have a dual role in systems development projects. Not only do they have a direct relationship with the perceived level of success associated with the CIS but they are also important facilitators for managing and developing user ownership and positive user attitudes, both of which are perceived to have a positive relationship with system success. An overview of the relationship between the adoption of best practice, the attainment of user ownership and positive attitudes and their resultant impact on system's success is presented in figure 1.

\section{$\underline{\text { Insert figure } 1 \text { about here }}$}

\section{Discussion of Findings}

Having reviewed the role of user ownership and positive user attitudes in influencing the successful application of community information systems, it is important to contextualise these findings within the relevant literature and in so doing, establish their contribution. Furthermore, the implications of this study, both for healthcare practitioners and IT professionals also need to be reviewed, as do the study's potential limitations. 
Whilst the importance of user ownership and positive user attitudes has previously been touched upon in the information systems literature (For example: Davis, 1993; Van Alstyne et al., 1995), their precise role and the mechanisms by which they are achieved has not previously been explicitly explored. Consequently, this research makes two significant contributions. Firstly, it confirms the importance of user ownership and positive user attitudes to the successful outcome of information systems projects through investigating a common organisation and system type. Secondly, and more importantly, it presents evidence that both user ownership and positive user attitudes have to be explicitly planned and then facilitated through the adoption of best practice; in essence they play an important mediating role between the adoption of best practice and the ultimate achievement of system's success. Despite the relatively small sample on which these findings are based, they are given added credibility when interpreted in light of the behavioural sciences literature, especially that concerned with organisational change. For example, Pierce et al. (1991) argue that motivation and positive behavioural responses to change are the result of 'psychological ownership' and Barbara Senior (1997) highlights the importance of creating positive employee attitudes, to reduce resistance to change initiatives. Furthermore, it is suggested that user ownership and positive user attitudes can be facilitated through employee participation (Bartkus, 1997), education and training (Kotter \& Schlesinger, 1979) and senior management commitment (Clarke, 1994).

These findings are of particular importance as they have a number of significant implications for the practice of information systems development and project management from both a healthcare and also a more general information systems perspective. Starting with the policy implications for healthcare professionals, the most recent NHS Information Strategy (Burns, 1998) suggests that clinicians: 'must deliver the new [IT] agenda', be part of a culture that is 'change focussed and able to take advantage of new technology' and have access to 'fast reliable and accurate information about the individual patients in their care'. The results of this research suggest that these policy objectives will only be achieved if levels of user ownership are improved and if individual users develop more positive attitudes towards information technology. Consequently, all future IM\&T projects within the NHS must adopt coherent change management strategies explicitly focussed upon the attainment of user ownership and positive attitudes, facilitated through active user participation, senior management commitment, high quality training and education and well-balanced project teams.

When it comes to the implications of this research for the wider practice of information systems development, any generalisations may have to be qualified. The UK’s National Health Service is an extraordinarily large and complex organisation, which is still very labour-intensive. It has very strong traditions, cultures and sub-cultures running throughout and is generally perceived as being slow to 
change (Handy, 1993). Consequently, when embarking upon change programmes, such as the introduction of new systems, managing the human resources and the behavioural issues is probably more important than in other contexts. Whilst, therefore, it is likely that attaining user ownership and positive user attitudes are generally important, especially in labour-intensive organisations, they may not be as important as they are within the NHS.

Research into the adoption of innovative technology, within the organisational context, is an ambitious undertaking and therefore contains a number of inherent limitations. In particular, the adoption of the in-depth case study format limited the number of organisations it was possible to target and hence reduces the generalisibility of the results. The selection of a small number of stakeholders at each Trust to participate in the study is also the source of potential bias. However, the variations in opinion recorded from the different informants and in particular, the negative comments provided by some clinicians, provided a strong indication that the results were not unduly biased, despite the IM\&T Managers acting as gatekeepers to informants. Furthermore, although each Trust typically has large numbers of clinical users, it was only possible to interview one from each Trust. However, the clinical user interviewed always reflected the main user group within the Trust and the clinical managers provided a further clinical perspective on the development and use of the system in each case. Finally, a further limitation relates to the scope of the study and the fact that it was not practical to study every possible variable that may have influenced the successful outcome of systems development projects. Consequently, although the study provides many interesting and novel insights, the aforementioned limitations should be taken into account when interpreting the results. Such limitations also highlight the need for follow-up studies, employing different methods, targeting different populations and focussing upon different combinations of variables.

\section{Concluding Remarks}

This paper provides an in-depth study of how information systems are being developed and applied within Community Trusts; an important, yet largely neglected research domain. It explicitly explores the role of user ownership and positive user attitudes and in so doing provides important new insights into how they can be achieved through the well-focused application of user participation, senior management commitment and high quality training and education. In a rapidly changing and ever more challenging organisational environment, where information technology plays an increasingly important operational and strategic role, such insights into the effective practice of information systems development have become critical. 


\section{References}

Audit Commission. (1997). A Study of Information Management in Community Trusts. London: Audit Commission for Local Authorities and the National Health Service in England and Wales.

Bailey, J.E., \& Pearson, S. (1983). Development of a tool for measuring and analysing computer user satisfaction. Management Science, 29(5), 530-545.

Bartkus, B.R. (1997). Employee ownership as catalyst of organisational change. Journal of Organisational Change Management, 10(4), 331-344.

Beynon-Davis, P. (1995). Information systems ‘failure': the case of the London Ambulance Service’s Computer Aided Despatch Project. European Journal of Information Systems, 4, 171-184.

Burns, F. (1998). Information for Health. Leeds: NHS Executive.

Cavaye, A.L.M. (1996). Case study research: A multi-faceted research approach for IS. Information Systems Journal, 6, 227-242.

Cerullo, M.J. (1980). Information Systems Success Factors. Journal of Systems Management, 31(12), 10-19.

Chesler, M. (1987). Professionals' views of the “dangers” of self-help groups. (CRSO Paper 345), Centre for Research on Social Organisation. MI: Ann Arbor.

Clarke, L. (1994). The Essence of Change. Hemel Hempstead: Prentice-Hall.

Clegg, C., Axtell, C., Damadoran, L., Farbey, B., Hull, R., Lloyd-Jones, R., Nicholls, J. Sell, R., \& Tomlinson, C. (1997). Information Technology: A study of performance and the role of human and organisational factors, Ergonomics, 40(9), 851-871.

Coombs, C.R., Doherty, N.F., \& Loan-Clarke, J. (1998). The factors determining the success of a CIS: A case study. Information Technology in Nursing, 10(3), 9-15.

Coombs, C.R., Doherty, N.F., \& Loan-Clarke, J. (1999). Factors affecting the level of success of community information systems. Journal of Management in Medicine, 13(3), 142-153.

Darke, P., Shanks, G., \& Broadbent, M. (1998). Successfully completing case study research: Combining rigour, relevance and pragmatism. Information Systems Journal, 8, 273-289.

Davis, F.D. (1993). User acceptance of information technology: System characteristics, user perceptions and behavioural impacts. International Journal of Man-Machine Studies, 38, 475487.

DeLone, W.H., \& McLean, E.R. (1992). Information systems success: The quest for the dependent variable. Information Systems Research, 3(1), 60-95.

Diamantopoulos, A., \& Souchon, A.L. (1996). Instrumental, conceptual and symbolic use of export information: An exploratory study of UK firms. Advances in International Marketing, 8, 117144.

Doherty, N.F., King, M., \& Marples, C.G. (1998). Factors affecting the success and failure of Hospital Information Support Systems. Failure and Lessons Learned in Information 
Technology Management, 2, 91-105.

Ennals, R. (1995). Preventing Information Technology Disasters. London.: Springer.

Faust, D. (1982). A needed component in prescriptions for science: Empirical knowledge of human cognitive limitations. Knowledge: Creation, Diffusion, Utilisation, 3, 555-570.

Flowers, S. (1997). Towards predicting information systems failure. In D. Avison, (Ed.), Key Issues in Information Systems, Maidenhead: McGraw-Hill, 215-228.

Gable, G.G. (1994). Integrating case study and survey research methods: An example in information systems. European Journal of Information Systems, 3(2), 112 - 126.

Galliers, R.D. (1992). Choosing information systems research approaches. In R.D. Galliers, (Ed.), Information Systems Research, London: Blackwell Scientific Publications, 144-162.

Ginzberg, M.J., Schultz, R., \& Lucas, H.C. (1984). A structural model of implementation. In R.L. Schultz \& M.J. Ginzberg (Eds.), Applications of Management Science: Management Science Implementation. Greenwich, CN: JAI Press.

Govindarajulu, C. \& Reithel, B.J. (1998). Beyond the information centre: An instrument to measure end user computing support from multiple sources. Information and Management, 33, 241-250.

Grantham, C.E., \& Vaske, J.J. (1985). Predicting the usage of an advanced communication technology. Behaviour and Information Technology, 4(4), 327-35.

Guimaraes, T., \& McKeen, J.D. (1993). User Participation in Information System Development: Moderation in All Things. In D. Avison, J. E. Kendall, \& J.I. DeGross, (Eds.), Human, Organisational and Social Dimensions of Information Systems Development. North Holland: Elsevier Science Publishers.

Handy, C.B. (1993). Understanding Organisations. $4^{\text {th }}$ edn, London: Penguin.

Hochstrasser, B., \& Griffiths, C. (1991). Controlling IT Investment. London: Chapman \& Hall.

Joshi, K. (1990). An investigation of equity as a determinant of user information satisfaction. Decision Sciences, 21(4), 786-807.

Joshi, K. (1992). A causal path model of the overall user attitudes toward the MIS function - The case of user information satisfaction. Information and Management, 22, 77-88.

Kearney, A.T. (1990). Barriers to the Successful Application of Information Technology. London: DTI \& CIMA.

Keen, J. (1994). Information Management in Health Services. Buckingham: The Open University Press.

Kotter, J.P., \& Schlesinger, L.A. (1979). Choosing strategies for change. Harvard Business Review, 57(2), 106-114.

Li, E.Y. (1997). Perceived importance of information systems success factors: A meta analysis of group differences. Information \& Management, 32(1), 15-28. 
Lucas, H.C. (1978). Empirical evidence for a descriptive model of implementation. MIS Quarterly, 2, 27-41.

Lucas, H.C. (1981). Implementation: The Key to Successful Information Systems. New York: McGraw Hill Book Company.

Lyytinen, K., \& Hirschheim, R. (1987). Information systems failures: A survey and classification of the empirical literature. Oxford Surveys in Information Technology, 4, 257-309.

Markus, M.L. (1983). Power, politics and MIS implementation. Communications of the ACM, 26(6) 430-444.

Miles, M.B., \& Huberman, A.M. (1994). Qualitative Data Analysis: An Expanded Sourcebook, 2nd Edn., London: Sage Publications.

Miller, J., \& Doyle, B. (1987). Measuring the effectiveness of computer-based information systems in the financial services sector. MIS Quarterly, 11(1) 107-124.

National Audit Office. (1991). Managing Computer Projects in the National Health Service. London: HMSO.

National Audit Office. (1996). The NHS Executive: The Hospital Information Support Systems Initiative. London: HMSO.

Pare, G., \& Elam, J.J. (1997). Using case study research to build theories of it implementation. In A. S. Lee, J. Liebenau, and J. I. DeGross, (Eds.), Information Systems and Qualitative Research, Proceedings of the IFIP TC8 WG 8.2 International Conference on Information Systems and Qualitative Research, 31 May-3 June 1997, Philadelphia, Pennsylvania, USA. London: Chapman and Hall.

Pierce, J.L., Rubenfeld, S.A., Morgan, S. (1991). Employee ownership: A conceptual-model of process and effects. Academy of Management Review, 16(1), 121-144.

Rademacher, R.A. (1989). Critical factors for systems success. Journal of Systems Management, 19(6) 15-17.

Robey, D., \& Farrow, D. (1982). User involvement in information system development: A conflict model and empirical test. Management Science, 28(1), 73-85.

Sauer, C. (1993). Why Information Systems Fail: A Case Study Approach. Henley: Alfred Waller.

Senior, B. (1997). Organisational Change. London: Pitman.

Srinivasan, A. (1985). Alternative measures of systems effectiveness: Associations and implications. MIS Quarterly, 9(3), 243-253.

Strauss, A.L., \& Corbin, J. (1990). Basics of Qualitative Research: Grounded Theory Procedures and Techniques. Newbury Park, CA: Sage Publications.

Van Alstyne, M., Brynjolfsson, E., \& Madnick, S. (1995). Why not one big database? Principles for data ownership. Decision Support Systems, 15, 267-284.

Whyte, G., \& Bytheway, A. (1996). Factors affecting information systems' success. International 
Journal of Service Industry Management ${ }_{2} 7(1), 74-93$.

Willcocks L., \& Margetts H. (1994). Risk assessment and information systems. European Journal of Information Systems, 3(2), 127-138.

Wong, E., \& Tate, G. (1994). A study of user participation in information systems development. Journal of Information Technology, 9, 51-60.

Yap, C., Soh, C., \& Raman, K. (1992). Information systems success factors in small business. OMEGA, 20(5), 597-609.

Yin, R.K. (1994). Case Study Research: Design and Methods. 2nd Edn, London: Sage Publications.

Zmud, R.W. (1983). CBIS failure and success, Information Systems in Organisation. Glenview, Illinois: Scott Foresman and Company. 
Table 1: Range of Informants Interviewed at Each Trust

\begin{tabular}{lccccc}
\hline Informant & Trust A* & Trust B & Trust C* & Trust D & Trust E \\
\hline IM\&T Manager & 3 & 3 & 3 & 33 & 3 \\
Manager & & 3 & 3 & 3 & 3 \\
Clinical Manager & & 3 & 33 & & 3 \\
Clinical User & 3 & 3 & 3 & 3 & 3 \\
\hline Totals & 2 & 4 & 5 & 4 & 4 \\
\hline
\end{tabular}

* Additional Documentary Information Provided

Table 2 Case Study Trust Profiles

\begin{tabular}{|c|c|c|c|c|c|}
\hline Trust Profile & Trust A & Trust B & Trust C & Trust D & Trust E \\
\hline \multirow[t]{3}{*}{ Service Provision } & Community & Community & Community & Community & Community \\
\hline & & Acute & Acute & Acute & \\
\hline & Mental Health & Mental Health & Mental Health & Mental Health & Mental Health \\
\hline Number of Hospitals & 3 & 7 & 4 & 5 & 5 \\
\hline $\begin{array}{l}\text { Number of. Health } \\
\text { Centres/Clinics }\end{array}$ & 11 & 16 & 42 & 8 & 7 \\
\hline $\begin{array}{l}\text { Staff Groups Using } \\
\text { System }\end{array}$ & $\begin{array}{l}\text { District } \\
\text { Nurses* } \\
\text { Health } \\
\text { Visitors } \\
\text { School Nurses } \\
\text { PAMS }\end{array}$ & $\begin{array}{l}\text { District } \\
\text { Nurses* } \\
\text { Health } \\
\text { Visitors* } \\
\text { School Nurses } \\
\text { PAMS }\end{array}$ & $\begin{array}{l}\text { District } \\
\text { Nurses* } \\
\text { Health } \\
\text { Visitors* } \\
\text { School Nurses } \\
\text { PAMS }\end{array}$ & $\begin{array}{l}\text { District } \\
\text { Nurses* } \\
\text { Health } \\
\text { Visitors* } \\
\text { School Nurses } \\
\text { PAMS }\end{array}$ & $\begin{array}{l}\text { District } \\
\text { Nurses* } \\
\text { Health } \\
\text { Visitors* } \\
\text { School Nurses } \\
\text { PAMS }\end{array}$ \\
\hline System Profile & Trust A & Trust B & Trust C & Trust D & Trust E \\
\hline System Name & Comwise & Comwise & Comwise & Comwise & Comwise \\
\hline Version & 2.2 & $\mathrm{~N} / \mathrm{S}$ & $2.2+$ & $\mathrm{N} / \mathrm{S}$ & 2.2 \\
\hline Supplier & $\begin{array}{l}\text { Systems Team } \\
\text { Ltd }\end{array}$ & $\begin{array}{l}\text { Systems Team } \\
\text { Ltd }\end{array}$ & $\begin{array}{l}\text { Systems Team } \\
\text { Ltd }\end{array}$ & $\begin{array}{l}\text { Systems Team } \\
\text { Ltd }\end{array}$ & $\begin{array}{l}\text { Systems Team } \\
\text { Ltd }\end{array}$ \\
\hline $\begin{array}{l}\text { Level of } \\
\text { Implementation }\end{array}$ & $\begin{array}{l}\text { Fully } \\
\text { Implemented }\end{array}$ & $\begin{array}{l}\text { Fully } \\
\text { Implemented }\end{array}$ & $\begin{array}{l}\text { Partially } \\
\text { Implemented }\end{array}$ & $\begin{array}{l}\text { Fully } \\
\text { Implemented }\end{array}$ & $\begin{array}{l}\text { Fully } \\
\text { Implemented }\end{array}$ \\
\hline $\begin{array}{l}\text { System Uses } \\
\text { Portable Technology }\end{array}$ & Yes & Yes & Yes & Yes & No \\
\hline $\begin{array}{l}\text { Staff Using the } \\
\text { System }\end{array}$ & $\begin{array}{l}\text { Clinical and } \\
\text { Clerical Staff }\end{array}$ & $\begin{array}{l}\text { Clinical and } \\
\text { Clerical Staff }\end{array}$ & $\begin{array}{l}\text { Clinical and } \\
\text { Clerical Staff }\end{array}$ & Clinical staff & $\begin{array}{l}\text { Clinical and } \\
\text { Clerical Staff }\end{array}$ \\
\hline
\end{tabular}

* Main staff groups using system N/S - Not Supplied


Table 3: Level of Adoption of Different Best Practice Variables at Each Trust

\begin{tabular}{|c|c|c|c|c|c|}
\hline Best Practice Variable & Trust A & Trust B & Trust C & Trust D & Trust E \\
\hline $\begin{array}{l}\text { Senior Management } \\
\text { Commitment and } \\
\text { Participation }\end{array}$ & + & + & + & - & - \\
\hline $\begin{array}{l}\text { Well Balanced Project } \\
\text { Team }\end{array}$ & + & + & + & & \\
\hline User Involvement & + & - & + & - & - \\
\hline $\begin{array}{l}\text { Management of User } \\
\text { Expectations }\end{array}$ & + & - & + & - & - \\
\hline User Training & + & + & + & + & - \\
\hline User Support & + & + & + & + & $\sim$ \\
\hline System Testing & + & + & + & + & + \\
\hline Success Score & 4 & 2.6 & 3.2 & 3.4 & 2.4 \\
\hline
\end{tabular}

Note: + denotes high occurrence of variable, - denotes low occurrence of variable, $\sim$ denotes moderate occurrence of variable. The overall measure of success is based on a 5 point Likert scale ranging from 1 , CIS is very unsuccessful to 5 , CIS is very successful. 
Figure 1: Diagram Showing the Relationships Perceived to Exist Between Best Practice Variables, User Attitudes, User Ownership and Their Impact on the CIS Project at Different Trusts

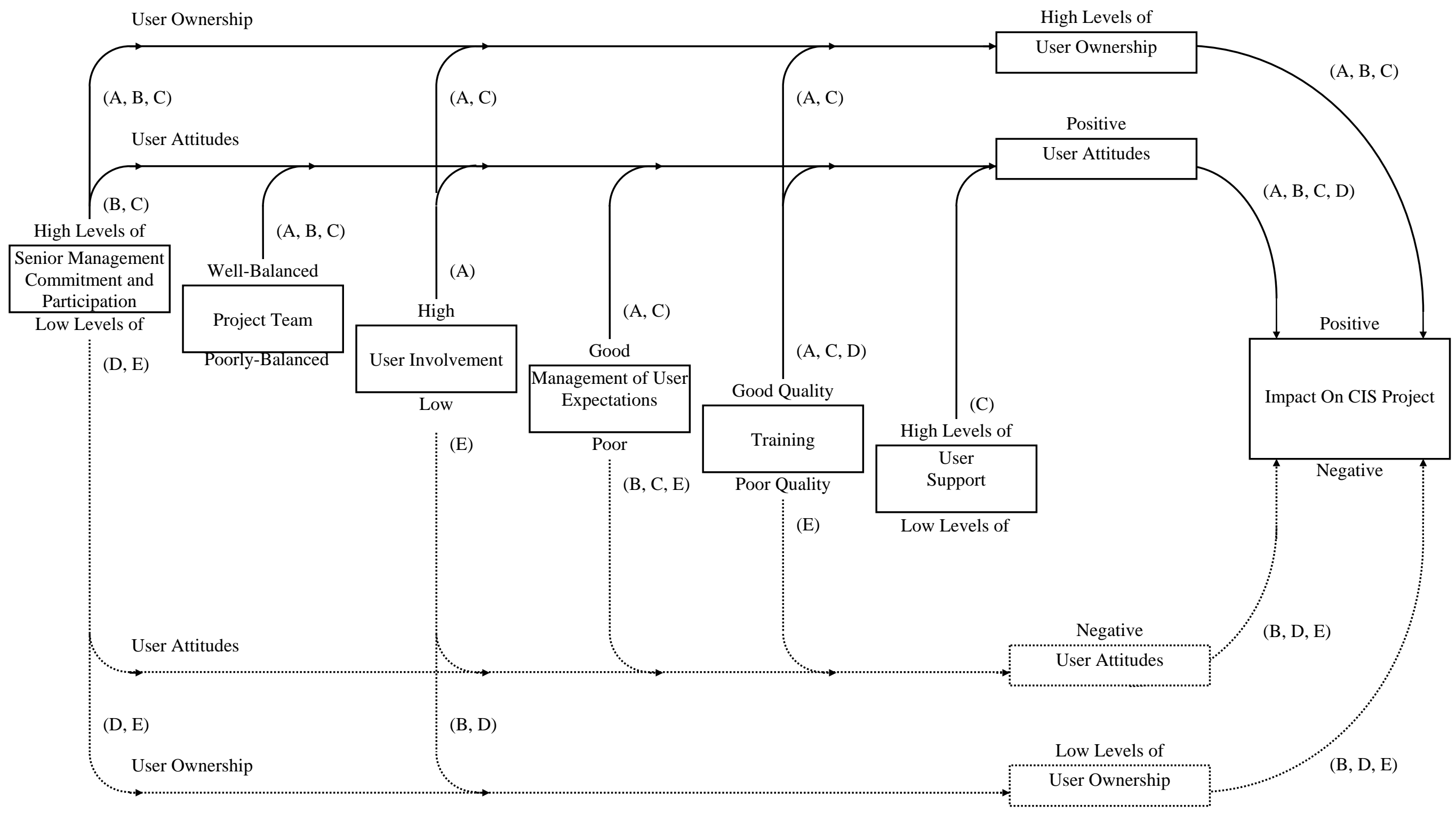

Note: Lines indicate where evidence of causality has been found at the Trusts highlighted in brackets 